Accelerator Department

BROOKHAVEN: NATIONAL : LABORATORY

Associated Universities, Inc.

Upton; L.I.: N.Y.

AGS DIVISION TECHNICAL NOTE

No. 30

J.C., Schuchman

February 2,1967

\title{
AGS VACUUM SEALS
}

The following meta1 vacuum seals are presently installed in the AGS as . shown below:

Quantity \& Description

(1) 'Lo-Load 8 1/2" I.D.

(1) : Lo-Load : . "

(1) TLo-Load $2: 1 / 4$ " I.D.:

(1) Lo-Load ", " "

(1) 0 -Ring 8 1/2"' I:D.

(1) o-Ring

*(1) 0 -Ring

*(1) O-Ring " "

(1) .:C-Ring 8 1/2"I.D...

(I) C-Ring

(1) C-Ring.

(1) C-Ring

(1) C-Ring

(1) $C-$ Ring
Location

E-17 Upstream,

$E-16 \% \quad "$

E-17:Ion Gauge

E-17 Moss Spec,

E-12 Upstream,

E-19 “ "

F-6 Downstream,

F-9 Upstream,

E-13 Downstream,

E-14 Upstream,

$$
\mathrm{E}-15
$$

E-15 :Downstream,

E-18.Upstream;

$\mathrm{E}-20$. "
Mating Flanges

Standard Chamber to Port-Box

Standard Chamber to $5 \mathrm{ft}$ Chamber.

Brass to $\mathrm{S} / \mathrm{S}$

$\mathrm{S} / \mathrm{S}$ to aluminum

Standard chamber to Bellows

$\begin{array}{lll}" 1 & 11 \\ " & " & \text { " }\end{array}$

Standard chamber to Port-Box

" " to 5 ' Chamber

" " to Bellows

11

II. to ' 5 ' Chamber

$"$

" to."

11

to Be1lows.

* These two seals were installed on Nov. 30 th, all others Feb. 1st. 
$-2-$

\section{Lo-Load: Sea1}

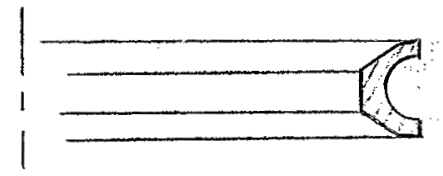

O-Ring Seal

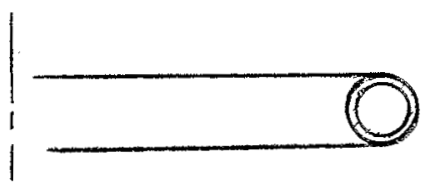

C-Ring Seal

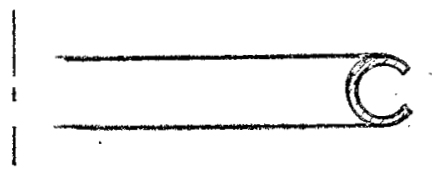

For on the spot identification the edges of the flanges were marked with ". colored ink pencils to identify the type of metal gasket used.

$$
\begin{aligned}
& \text { Blue for Lo-Load seal } \\
& \text { Green " } \text { o-Ring seal } \\
& \text { Yellow. "C-Ring seal }
\end{aligned}
$$

A more complete report of the AGS metal seal status and development will follow:

Distribution:

V. Buchanan

R. Dryden.

C. Gould:

J. Grisoli

D. Hoober.

C.' Lasky:

A. Maschke

I. Polk

A. van Steenbergen 